\title{
Desafios na Formação de Tutores Sócio-interacionistas para EAD
}

\author{
Cristiane F.de Aguilar * \\ Elaine R.Maurício de Souza" \\ Cleia S. Fodrigues \\ Marta Cardoso.L. C. Rego \\ Raquel M. Villardi
}

\begin{abstract}
Resumo: Este estudo relata urna experiência de forthaça conthuada de profossores a distancla, a partir da problematizacaso do ens/no da linguagom. no ambito das escolas de nivel fundamental do Estado do Filo de Janeire, na busca de nowos caminhos que viabilizent uma ofetiva mollorio no sistema edugacional, de modo que os professores, alèm do mero alo de ensinar, estejan aptos a contributr

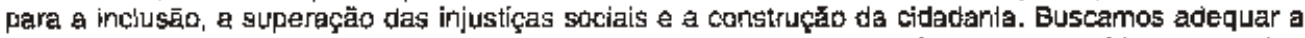
perspectiva teorico-metododogica adotada zo uso de novas tecnoiogias no ambiente escolar, dosenwolvendo um sistema mútiplo em EAD, baseado no conceito de réde.
\end{abstract}

Um curso de tormação continusda etr etucaçăo matemética, para professores de Educacio lriantil, servils de ponto de pertide para a definiçüo de um modelo de formaça de tutores. Inicialmente, foi realizado um teste de bancada com os futuros tulores e, a partir da análise da comuricaça e da interaça promovidas nesse percurso, buscamos feramentas que favorecessem a clareza da linguagem no curso.

Dafinimos que, antes de atuar como orientador da aprendizagem, o tutor viwenciasse o processo como alung, prassando por todas as dificuldades que os futuros alunos do aurso pudessern encontrar, ostando, assim, capacitado a min|miza-las.

Defirimos, |gualmente, as furçōes a o lugar especffico do tutor: estimular a reflexăp, propiciar conhecirsentos a subsidiar a açä, minimizanco as dúvidas e reforcando o potencial de entendimento de cada individuo. E necessirio que esteja em contato permanerite com ds alunos, no acompanhamento das tarefas propostas, verificando a participaça nos toruns. Enflm, dele dependo a motivaça do aluno no cuturso e sua aprendizagenm gignificativa.

O procosso demonstrou ser possivel aprender a distancia em interacaso com outros, em ambiente virtual. Para isso, foi fundamental a açăo de um professor on-line (tutor) capacitado para traballhar sob esta perspectiva educative, dinamizador do ato de aprender, dotado de uma forthaça crítica e capaz de criar espaços em que o estudante desenwolva a autonomia, promovendo interaçes e mantendo os alunos motivados en tomo de sua própria aprendizagem.

Porntitiu concluir: ainda, que, uma tutoria interativa, afetiva e dinarrizadora, se constitui corno fator fundamental no sucesso de cursos a distencla que utilizem ambientes virtuais, lace ao al to numero de evasōes our, ainda agsim, os tursos apresentam.

Palavras Chave: Educaçăo, Tecrologie, Tutoria, Comuricaçăo e Interatividade

Resume: This study describes a distance teachers cohtlnuous formation experlence, beglinhling from the problem with the language learning, among the high schools in the State of Fio de wameiro, and the search for new ways that coutd provide an improvement on the educational systerm - we'we passed through a continuous formation of leachers, so that, owar the mere act of teaching, they're apt to contribute to the inclusion, the overcome of social injustices and the construction of citizenship. We tried to adequate the theoric-methodological perspective adopted to the use of new tecnologies on the scholar ambient, developing a multipla system in DL, based an the concept of nework.

A continuous formetion course in Mathematic, for Childish Education teachers, serwed an starting point to defirne a model for tutors formation. First, it was made a workbench test with the futire tutors and, trom the analysis of the comurication and the interection promowed in lfiris course, we searched tools that favored the clarity of the language In the cousse.

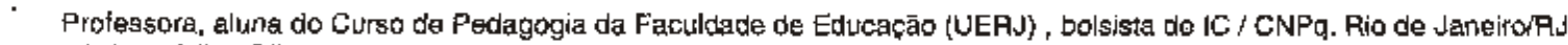
cristiane.fallah wibest.com.br

Professora, aluna do Curso de Pedagogla da Faculdade de Educaçāo (UERJ) bolsista de lD / Rio de daneiro/RJ elaregiebol.com,br

“" Pedagoga, Bolsista de Apoio Tecrico (FAPERJ) / Faculdade de Educaçāo (UERJ) Fio de Janeiro/R cleiarodrigues o hotmail.corm

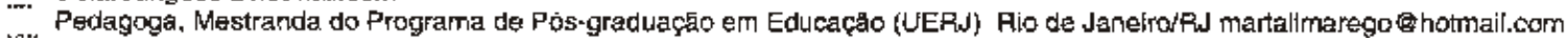

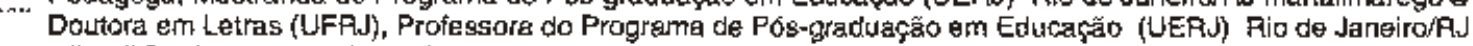

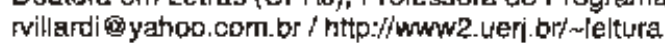


It's necessary that betore acting as an apprendlzation gulde, the tutor paric|pates of the process as a student, passing through all the difficulties that the future students of the pourse may find, fhis way bern capable to mimimize tharn to the max.

The process showed that it's possible to learn at distance, interacting with others in a witual amblent. To thls its necessery an on-line teacher (tutor) capacitated to work in this educational pratic, making the act of leam more dymamic, endowed with critic formation promoting space for the studert io dewelop autonomy to les be bysmic and an interactive promoler, maintaining the students motivated around their outh leaming.

It showed, also, that an Inieractwe, affectwe and dynamic tutelage, is constituted as a fundarlental factor in the success of distance colvses that utilizes virtual environments, in spite of the high mumber of ewasions that this courges still have.

Key-Words: Edweation, Tecnology. Turelage, Communication e Imleractivity

\section{Educação e Tecnologia}

A impossibilidade de fomeçăo profissional fora dos centros urbanos, num país de grandes dimensóes como o nosso, foi, desde sempre, uma das grandes causas - embora pouco lembrada - da perspectiva da exclusão social que tem estado no ámago do processo de desenvolvimento social do nosso país.

O questionamento da esçcola convencional, que começara no inicio do século e se acentuata nos anos 60 , com correntes de idéias qualificando o sistema escolar como "fechado", "monopolizador" e "marginalizador", deu origem a movimentos inovadores para incorporar novos métodos e modalidades de ensino que rompessem as tronteiras das limitações físicas e metodológicas da escola.

Ao longo desse tempo, o enfoque dado ao uso das tecnologías, na educação, se altera, de acordo com a finalidade e com a mídia privilegiada pela sociedade, a cada momento de intervençăo. Dessa forma, a inserção da techologia no cotidiano da escola já nos parece irreversivel, tanto pelo processo inexoráveł de absorção dessa tecnologia, por que passa a cultura, quanto pela desqualificaçāo dos discursos a ela antagónicos. Nessa meșma perspectiva, sobressai a importância de uma escola que desenvolva uma nova competência, que se fundamenta numa das habilidades cognitivas básicas: a da seleçāo. Mas isso requer a disseminação, por todo o paiss, de um professor formado para educar nāo mais a partir da transmissäo de informaçóes, mas pelo desenvolvimento das potencialidades do aluno.

Nessas circunstäncias, è preciso pensar numa forma de levar educaçăo aos profissionais que estāo distantes dos centros urbanos, com um padrão de qualidade igual ou melhor ao da educaçāo ministrada nas escolas de educaçăo presenciał. Asssim, educaçāo a distancia se torna urna alternativa viável para, pela sua utilizaçāo nos setores educacionais públicos e privados.

Com o aprimoramento da tecnołogia da comunicação surgiu também a expectativa de que novos materiais de apoio viessem a ser incorporados na educaçäo a distância. Os novos recurşos tecnológicos vêm modificando, estruturalmente, os ambientes de aprendizagem. Tal alternativa, como era de se esperar, tem sido alvo de muitas críticas, que de alguma forma reduplicam as trazidas pelos apocalipticos (Umberto Eco, 1976), que durante décadas viram nessa opção uma via de desmoronamento da cultura, com conseqüéncias destrutivas para a própria dimensão humana.

\section{Em busca de novos caminhos para melhoria do sistema educeclonal}

Nossas investigaçōes anteriores (Villardi, 1997; Villardi, 2000) revelaram a necessidade de investir na formação continuada de professores, de modo a torná-los aptos a atuar no trabalho com o desenvolvimento lingüistico de seus alunos, especificamente no que se refere ao campo da leitura $\theta$ da escrita. Como o acesso à variedade culta da língua se dá pela apropriação de estruturas lingüisticas complexas, que dependem do desenvolvimento da faculdade mental da linguagem (Saussure, 1969), $\dot{\theta}$ papel da escola fornecer ao aluno as condiçóes para que tal apropriaçäo ocorra. Úma vez desenvolvidas, o 
sujeito será capaz de ler qualquer tipo de texto e, conseqüentemente, Jer o mundo, de foma crítica, construindo assim sua cidadania (Foucambert, 1994).

Investigando mecanismos que viabilizassem a utilizaçăo desse conhecimento diretamente na sala de aula, buscamos adequar a perspectiva teónco-metodológica, que já vem sendo adotada pelo grupo de pesquisa (Villardi, 1997), ao uso de novas tecnologias no ambiente escolar. Desenvolvemos um sistema míltiplo em EAD baseado no conceito de rede, a partir do qual passamos a oferecer cursos de educaçāo continuada a distáncia como uma possibilidade concreta de atingir os profissionais da Educação que estão distantes dos centros urbanos. É fundamental oferecer a esses profissionais o referencial teórico necessário para a materialização de uma verdadeira transtomação da prática pedagógica, $\theta$, conseqüentemente, da Educaçào como um todo. Utilizamos um sistema didático-metodológico-computacional múltiplo, viabilizando o desenvolvimento das habilidades cognitivas a partir do uso da linguagem em diferentes códigos, delineando uma proposte interativa que valorizasse a construçào do conhecimento.

Fó desenvolvido, inicialmente, um protótipo de curso de formaçāo continuada a distância em Matemática. A escolha das ferramentas de interaçăo incorporadas ao sistema foi baseada no estudo da aplicabilidacie e da funcionalidade de cada uma delas. A partir disso, definimos os fóruns como espaço de troca de experiências e construçăo do conhecimento, com discussōes que se travavam a partír do estágio de construçăo de conhecimento em que se encontrava cada grupo de alunos, a partir de questoes propostas pelo professor-autor do curso; as listas de discussâo efetivavam a comunicação com todo o grupo; os e-mails constitulram o canal para a comunicação individual aluno-tutor e as salas de estudos, um espaco para trocas informais.

\section{O tutor no processo construcloniste}

Tem sido dificil encontrar o lugar do tutor no processo construtivista, onde o aluno ocupa o centro do processo, já que o tutor de hoje năo é um mero tirador de duvidas, mas assume papet fundamentał e determinante em todo o processo, ao contrário do que ocorria quando a EAD se resumia nas apostilas elaboradas para a aluno estudar sozinho. Assim, buscamos oferecer uma capacitaçāo de tutores que os transformasse em efetivos mediadores do processo de aprendizagem, que foi dividida em duas etapas.

A primeira etapa na formaçäo do tutor constituiu o dominio de um supotte teórico que fundamenta o processo educacional construcionista. Ele deve possuir uma concepção de educaçāo fundamentada na abordagem sócio interacionista (Vygotsky, 1989) que concebe a aprendizagem como um fenômeno que se realiza na interaçăo com o outro.

O conceito de zona de desenvolvimento proximal remete-nos à reflexảo sobre o papel do professor e dos demais colegas - incluindo, ai, o tutor. Para Vygotsky existem dois niveis de conhecimento: o real e o potencial. No primeiro o indivíduo 6 capaz de realizar tarefas com independéncia, e caracteriza-se pelo desenvolvimento já consolidado. No segundo, o individuo só é capaz de realizar tarefas com a ajuda do outro, o que denota desenvolvimento, porque nēo é em qualquer etapa da vida que um individuo pode resolver problemas com a ajuda de outras pessoas.

Partindo desses dois miveis, Vygotsky define a zona de desenvolvimento proximal como a distância entre o conhecimento real e o potencial; nela estão as funçóes psicológicas ainda näo consolidadas.

E um domínio em constante transformação, pois aquilo que se é capaz de fazer com a ajuda do alguém hoje, será possivel fazer com autonomia amanhä. Como o desenvolvimento năo acontece igualmente para todos, pois depende fundamentalmente das experiencias sociais de cada um, o tutor deve atuar como um problematizador, ou seja, aquele que organiza as interaçóes dos alunos com o meio, problematizando as situaçós vividas por eles. Portanto, se ao tutor cabe mediar o processo de construçăo de conhecimento, é preciso que sua atuação coloque os alunos, mesmo distantes no espaço e $/$ ou no tempo, em zonas de desenvolvimento proximal.

Assim, para além de um conhecimento teórico, cada tutor precisa ser alvo de uma formaçäo sóciointeracionista capaz de desconstruir um paradigma tradicional de aensino», de que ele foi alvo ao longo de sua vida de estudante, para implantar um paradigma em que o locus do professor se desloca, instaurando a figura de urn mediador, que näo ensina, mas que viabiliza a aprendizagem. 
A essa formaçāo, na primeira fase da capacitação dos tutores, foi associado todo um aporte na área da psicologia da comunicą̧ăo, e que buscou prepará-los para maximizar os niveis de comunicabilidade entre tutores alunos, evidenciando aspectos afetivos e emocionais que cercam a EAD.

A segunda etapa trata do domínio do conteúdo. E necessário que o tutor conteça a fundo os conteúdos a serem apresentados, e conheça-os de forma atualizada. $O$ conteúdo é o dado da realidade, e como tal, será sempre algo vivo, rico em sugestóes e em caminhos de intepretação e de aprofundamento, abrindo espaço de reflexäo e de troca de experiências e de informaçöes para facilitar a construção de conhecimentos.

Numa terceira etapa é imprescindivel que antes de atuar como crientador da aprendizagem o tutor vivencie o processo como aluno, realizando as atividades propostas, a firm de verificar a clareza, a comunicabilidade e as possiveis dificuldades que os alunos possam encontrar, estando capacitado para minirmizá-las.

\section{Formação e atuaçāo dos tutores}

Foi reatizada uma pesquisa de campo por uma equipe multidisciplinar composta por sete bolsistas de Pedagogia, um professor de Matemática, um professor de Letras e três bolsistas de Informática, qule resultou na construçäo de conhecimento teórico e prático, com a vivencia dos fatos e nāo apenes suposiçōes e especulaçōes, num processo de rélexāo-açắ.

As bolsistas do curso de Pedagogia, todas professoras das séries iniciais do Ensino Fundamental, participaram da elaboraçāo e construçāo do material didático e do processo de formaçāo do tutor, que foi dividido em trés etapas. Na primeira, realizou-se um estudo térico metodologico, onde abordamos a funçāo do tutor em um curso EAD, de modo a defini-lo năo como um treinador, mas como educador sob a perspectiva sócio interacionista. A segunda etapa envolveu a participação dos futuros tutores no curso, desempenhando o papel de alunos. Tiveram, assim, a possibilidade de fazer uma análise crítica do processo. Tal análise originou demandes por mudanças na navegabilidade e na comunicabilidade do curso, e resultou na definiçāo de padrōes de atuaçăo que garantissem a interaçāo e comunicabitidade. Esse procedimento fundamentou a açāo dos tutores como educadores, estabelecendo métodos de mediaçáo, interação e estímulo. Somente na terceira etapa houve a atuaçăo real dos boisistas como tutores do curso.

E fundarnental que toda proposta de EAD siga essa perspectiva. Durante a preparaça do material didático, foi preciso objetivar as seguintes caracteristicas: clareza, do ponto de vista da linguagem; comunicação imediata com o interlocutor; interaçăo entre a interocutor e material; e estímulo à troca de experiencias com os colegas de curso.

Com base em um estudo sobre a aplicabilidade e funcionalidade cada uma das ferramentas de interação, concluimos quais deveriam ser utilizadas no curso. Definimos entāo, os fóruns como espaço de construçäo do conhecimento, a partir da troca de experiencias, abrindo discussöes sobre o tema, fundamentadas nas indagaçóes propostas pelo professor autor do curso; as listas de discussäo tornavam possivel a comunicaçăo com todo o grupo. Os e-mails possibilitaram a comunicaçáa individual, alurio-\$utor, e salas de estudo como um espaço hvre de interação entre todos os participartes. Escolnemos ferramentas. de interação que facilitassem o aluno, como fóruns e e-mails em português, acesslveis na internet gratuitamente. Os alunas que fizeram o curso off-line usavarn a rede apetras para acessar as ferramentas de interação no taboratório da faculdade.

A formação dos tutores fọ reatizada durante o teste de bancada, de modo que o tutor foi o primeiro aluno do curso. A definiça da fomaçäo tutorial, nessa perspectiva, objetivou uma tentativa de identificar, minimizar e solucionar possiveis problemas e dificuldades que seriam encontradas posteriormente, pelos alunos, quando o curso estivesse em rede. Esse procedimento nos possibilitou a reformulação e o redimensionamento de algumas propostas, na busca da compreensão e da comunicabilidade. Partindo do experimento com o grupo de tutores no teste de bancada, chegamos à conclusão de que era necessário um arquivo com normas gerais sobre o acesso ao curso, bem como a disponibilizaçáo de um arquivo de ajuda sobre a utitização das ferramentas de interaçăo, o quat foi colocado à disposiçăo dos alunos no próprio ato de ínscriçăo no curso.

Acreditamos que a formaçäo do tutor seja altamente relevente, e que seja preciso que, antes de agir como orientador da aprendizagem, ele vivencie o processo como alutio, que passe por todos os momentos 
e dificuldades que os alunos dos curso encontrarão, estando assim apto para esclarecê-los ao máximo, bem como a intervir para criar espaços diferenciados de aprendizagem.

Como tado o curso foi oferecido sem que dispuséssemos de uma plataforma de software como suporte, desenvolvemos um mecanismo de controle administrativo para que o professor e o tutor pudessem acompanhar a situação dos alunos, desde a inscriçäo até a conclusão do curso.

Finalmente, construímos um siștema de avaliação e análișe de resultados, que mesclava a avaliaçăo do professor - por meio dos trabalhos recebidos e da análise da participação de cada ałuno nos espaços de interaçāo - peia auto-avaliaçāo e peia avaliaçâa dos colegas. Os procedimentos metodológicos utilizados fundamentam-se nos principios da pesquisa-ação.

A atuação do tutor em cursos de educação a distância é de fundamental importância, não somente no que se refere ao dominio dos conteudos, como também, à habilidades de relacionamento com os alunos, utilização adequada dos meios, como estratégias e ferramentas para interaçăo a distância e veriffcação da viabilidade de construçăo de um ambiente de aprendizagem.

É impontante que tenha formaçăo crítiça, promovendo espaço para que o estudante desenvolva autonomia para aprender, seja dinamizador, promotor de interaçōes, mantendo os alunos motivados em tomo de sua própria aprendizagem.

$O$ tufor tern de construir um vinculo afetivo com o aluno, saber de suas dificuldades, seus gostos, seus objetivos, para que o aluno se sinta motivado a continuar o curso. $O$ papel do tutor é estimular a reflexão, propiciar conhecimentos e subsidiar a açäo, minimizando as dúvidas e reforçando o potencial de entendimento de cada indivíduo. E necessário que esteja em contato permanente com os alunos, no acompanhamento das tarefas propostas, verificando a participaçāo nos espaços de troca. Enfim, dele depende o acompanhamento, a motivaçăo e a permanência do aluno no curso.

Como resultado preliminar, citamos a necessidade de construção de uma rede de interação. $O$ trabalho, dentro de uma equipe multidisciplinar com pessoas das áreas de Educação, Letras e Informática, onde várias as etapas do processo foram planejadas e experimentadas, gerou um ambiente de aprendizagem onde foi relevante o tanto que um aprendeu com o outro. Isto confirmou nossa hipótese acerca da necessidade de interaçăo para a construçāo do conhecinento já nos primeiros momentos do processo.

O papel do tutor é fundamental e determinante em todo processo. Favorece relaçóes de confiança e segurança a serem estabelecidas durante o processo de formação. Essas relaçōes são necessárias para o embasamento de sua atuação em todos os momentos do curso. Nossas pesquisas haviam verificado experiências sobre a atuaçāo dos tutores que ainda ficavam atreladas aos modelos de instruçäo programada. Na nossa proposta de formaçảo, objetivamos a garantia de um desempenho que foi fundamental tanto no acompanhamento dos alunos, quanto na efetivação da compreensâo e comunicabilidade em todo o processo.

O tutor formado na nossa perspectiva representou um diferenciat no processo de construçāo do conhecimento.

Năo se pode abrir mäo da proposta de que os tutores sejam, os primeiros alunos do curso, particjpando como co-autores, vivenciando o processo de construçăo do protótipo para atuar como mediadores, criando um ambiente de interação compreendida como processo de afetaçä́o mútua, que caminha por duas vertentes: o emocional - com a integraçăo social e motivaçăo - e o cognitivo, no que diz respeito aos desafios, apoio $\theta$ estratégias para o melhor desempenho na processo de ensino/aprendizagem.

Nesse sistema múltiplo computacional, garantimos o sucesso do curso proposto, com a construçăo coletiva da aprendizagem para os alunos que o concluiram. Estamos em processo de análise dos dados obtídos, para posterior elaboração de gráficos e tabelas que nos permitam consolidar nossas hipóteses acerça da importảncia da formaçäo e atuaçăo dos tutores nos cursos de educação a distânçia.

A luz dos dados obtidos, podemos afirmar ser possivel oferecer educaçáo a distância, com uso de tecnologia, que se diferencie das propostas de instruçăo programada de treinamento a distāncia. Confirmamos a possibilidade de aprendizado a distância, em interaçăo com outros, com autonomia, independentemente da relação espaço-tempo. Tal constatação nos proporciona maiores possibilidades de alcançar o corpo docente da rede pública, no que diz respeito à formação continuada, na busca de uma açäo pedagógica eficaz, na área da linguagem, que rompa as fronteiras das limitações físicạs e metodológicas da escola. 


\section{Reterências bibliográficas}

ECO, U. Apocalipticos e Integrados. Sāo Paulo: Perspectiva, 1976

ESTEVES, Antonia P.\& OLVEIRA, Gabriela D. Educaçăo a distáncla: Experlência Unlversltárias, Rio de Janeiro, Lidedor, 2001.

FOUCAMBERT, Jean. A leitura em questảo. Porto Alegre: Artes Médicas, 1994.

SAUSURAE, F.Curso de Lingüística Geral. Sào Paulo: Cultrix, 1969.

VILLAFDh, Raquel. Ensinando a gostar de ler e formando leitoreg para a vida inteira. Rio de Janeiro, Dunya, 1997.

VILIARDI, Raquoi. Desenvolvimento de Slstema Interativo para Formaģa Docente, Flo de Janeiro,2000

VILLARDI, R; OLIVEIRA, E G.; GAMA, Z.j. EdLçaçăo a distância: possibilidades e entraves ì democratizaçăo do acesso à educaça superior públita, gratulta e de qualidade no Brasil. Revista Advir, Rio de Janeiro, v. 14, p.3137,2001

VYGOTSKY, Lery S. A Formaçáo Social da Mente. São Paulo: Martins. Fontes, 1989. 